\title{
USING THE PROJECT METHOD TO IMPROVE THE EFFICIENCY OF A FOREIGN LANGUAGE LESSON
}

\author{
Ermatov Usmonjon Komilovich \\ Senior Lecturer \\ Department of Translation Theory and Practice, Faculty of Translation \\ UzSWLU Tashkent, Uzbekistan
}

\begin{abstract}
The article discusses the theoretical significance of the project method in foreign language lessons. It theoretically substantiates the possibility of a more effective way of improving the communicative competence of students at the middle stage of teaching foreign languages using the project method. The possibility of using the project method to improve motivation, the development of the cognitive interests of students, the abilities of self - and mutual assessment was revealed, and criteria for external assessment of all types of projects were developed based on the parameters existing in the methodology. The typology of projects in foreign languages has been clarified.
\end{abstract}

Key words: project method, improving motivation, educational and cognitive techniques, the formation of communicative competence, practical mastery.

\section{Introduction}

In recent years, the project method has become more and more widespread in teaching practice, including teaching foreign languages. It is interpreted differently by methodologists and teachers. We adhere to the following definition of this method: "The project method presupposes a certain set of educational and cognitive techniques that allow you to solve a particular problem as a result of students' independent actions with the obligatory presentation of these results. If we talk about the project method as a pedagogical technology, then this technology presupposes a set of research, search, problematic methods, creative in their very essence.

The popularity of the project method is due to the fact that, due to its didactic nature, it allows solving problems of developing the creative capabilities of students, the ability to independently design their knowledge and apply them to solve cognitive and practical problems, navigate the information space, analyze the information received, since at different moments of cognitive, experimental or applied, creative activity, students use the totality of all the listed intellectual skills and abilities. The main goal of teaching foreign languages is the formation of communicative competence, which provides not only practical knowledge of a foreign language, but also the ability to work with information: printed, sound in different media, i.e. possession of the skills of critical and creative thinking.

Consequently, we are talking about a certain organization of the content of education and cognitive activity of students, which would facilitate and accelerate the mastery of knowledge by students, activate the process of their assimilation, teach schoolchildren the techniques of independent work with educational material and information, contribute to the formation of information and communicative competencies in them. To realize the goals of the modern education system, world pedagogy has taken a focus on a personality-oriented approach. Along with such methods as teaching in cooperation, discussions, role-playing games of a problematic orientation, the "Student Portfolio" method of projects most fully reflects the basic principles of a personality-oriented approach, based on the principles of the humanistic direction in psychology and pedagogy. By its very nature, the project method presupposes the need to differentiate learning, focus on the student's personality, his needs and capabilities, is based on the principles of cooperation and the inclusion of students in active activities.

\section{Main part}

The use of the project method in teaching allows students to use a foreign language as a means of cognition, a way of expressing their own thoughts, perception and understanding of the thoughts of other people. This is the most effective way to switch students' attention from the form of expression to the content and to get involved in the knowledge of the world around them by means of a foreign language, thereby expanding the scope of sociocultural competence.

Of course, the effectiveness of using this method largely depends on its detailed, technological development for a certain stage of training, the study of a whole complex of tasks related to the specifics of the subject area, the level of training, the standard of education in foreign languages, because the effectiveness of using one or another method in educational the educational process directly depends on the literate, i.e. methodologically sound use of it. In addition, the widespread introduction of the project method into the educational process recently often leads to the substitution of concepts.

Method is a didactic category. This is a way of organizing the process of cognition, mastering a certain area of practical or theoretical knowledge. Therefore, if we are talking about the project method, then we mean exactly the way to achieve the didactic goal through the detailed development of the problem (and this is nothing but technology). For a foreign language, this is important from the point of view of speech-thinking activity. Discussion, consideration of a 
problem with the aim of solving it stimulates speech-thinking activity. The project method is one of the ways to increase the effectiveness of the formation of foreign language communicative competence, the development of the cognitive interests of students, the intellectual skills of critical and creative thinking, the ability of self - and mutual assessment. Speaking about communicative competence in the field of a foreign language, we mean the ability and willingness of students to use a foreign language in a variety of communication situations in accordance with the norms of a given language, when working with foreign language information in the body of knowledge of sociolinguistic and sociocultural plans. In addition, the focus of the learning process on the practical mastery of a foreign language aims not only to prepare the student for foreign language communication within the limits set by the program, but also to contribute to the formation and development of a personality capable of making non-standard decisions so that the knowledge acquired by the student becomes a tool for revealing his intellectual, spiritual and creativity, not an end in itself of learning rethinking traditional approaches to education has become the central idea of a radical restructuring of the modern school and numerous reform programs and concepts in the field of education in recent decades, which have taken a focus on a person-centered approach. The focus on the student's personality also determines the modern concept of language education, the main trends of which are:

- Person-centered approach to teaching foreign languages;

- the formation of communicative, socio-cultural and compensatory competencies, ensuring the development of critical thinking, socialization of the personality of students, based on the problematic nature of the learning process;

- the need to familiarize with the image of consciousness of another people through the dialogue of cultures;

- building the process of teaching foreign languages on an activity basis.

The most relevant pedagogical technology capable of ensuring the solution of the tasks set before education is the project method. Having appeared at the beginning of the last century to solve educational problems that were relevant for that time, the project method has not lost its relevance today. It is from the point of view of the problem of adapting the school to modern economic realities, from the point of view of its practicality, the method of projects is of certain didactic interest for us. In the traditionally established practice of teaching foreign languages, the achievement of practical and developmental goals of teaching foreign languages is difficult, since the currently implemented teaching methods do not sufficiently take into account the psycholinguistic features of the subject "foreign language" and the objective laws of its teaching. From the point of view of psychology, mastery of speech activity occurs only when the need for speech communication is embodied in the subject of this activity - thought. Therefore, we need situations that would be based on the exchange of thoughts, and language would become a means of forming and formulating these thoughts.

Priority should be given to such methods, teaching techniques that could provide a sufficient amount of oral practice to each student of the group in the classroom, and at the stage of creative application of speech material could provide communication of students based on the exchange of views, thoughts about a particular problem situation, knowledge by students features of the functioning of a foreign language in a culture new to them. The project method, due to its didactic nature, allows solving these problems. It is based on the idea of the orientation of educational and cognitive activity on the result, which is achieved through the solution of one or another practically or theoretically significant problem for the student. Analysis of the main methodological and theoretical approaches to the study of possible ways of using the project method as an effective means of forming communicative competence showed that the project method in the process of learning a foreign language allows you to integrate various types of foreign language verbal communication to solve certain information, research problematic tasks.

The project activity puts the student in a situation of real use of the studied language, makes it possible to shift the emphasis from the linguistic component to the substantive one and focus their attention not on the language, but on the problem, contributing to the awareness of the goals and possibilities of learning a foreign language, including the process of mastering a foreign language into productive creative activity.

At the same time, the educational process is built not from the point of view of the priorities of the educational material, but from the point of view of the development of the student's personality, based on his interests, abilities, opportunities. The study of the age characteristics of students of secondary school age in order to determine the effectiveness of this method for the formation of their communicative competence, the development of potential abilities and capabilities showed that the level of intellectual and mental development achieved by students indicates that they have a potential, based on which it is possible to optimize the process of formation their communication skills. The amount of knowledge, skills and abilities mastered, the experience of cognitive activity of students of this age are sufficient to increase the level of independence at the stage of project implementation. The project method creates conditions under which students learn group interaction and acquire communication skills, which is important for the socialization of students, especially in adolescence, since the system of relations with peers, the desire to be socially significant is very valuable for adolescents. On the basis of "the central psychological neoplasm - the feeling of adulthood - the adolescent's thinking becomes more independent, creative, critical thinking is formed" [3]

Consequently, adolescents can, in a sense, actively participate in the selection, organization and design of educational content. The intensive development of formal-logical thinking makes it possible to shift the emphasis from the assimilation of a certain set of skills and abilities by students, when learning occurs through the exploitation of memory, to the independent acquisition of them by involving students in the process of finding a solution to the problem. It is quite obvious that the project method, being a complex method, inherently involving the use of a wide range of problematic, research, search methods, training in cooperation, is able to solve a whole range of problems 
related to the optimization of the educational process in a foreign language, provided that the basic requirements are met. to its use. One of these requirements is knowledge of the typology of projects, since the organization of project activities is largely determined by the type of project. Based on the general didactic typology of projects developed by E.S. Polat, M.Y. Bukharkina proposed a typology of telecommunication projects in teaching foreign languages, which, from our point of view, can be partially attributed to projects carried out outside the network. However, the specificity of the subject "foreign language" dictates the need to introduce some clarifications into the developed typology of educational projects in foreign languages. This is due to a number of reasons:

Firstly, possession of sociocultural competence means knowledge of the national and cultural specifics of speech behavior, the system of cultural and social relations and the sociocultural portrait of the countries that speak the target language.

\section{Conclusion}

In this regard, such types of projects as "philological" and "culturological" were combined into "sociocultural", since they are designed to acquaint students with the national and cultural characteristics of the countries of the target language. In addition, the study of some topics provides for the discussion of issues related to the problems of relationships between people, their tastes, views, etc., which made it possible to additionally highlight the "social" type of projects. Of course, in the further development of the typology of projects, there were signs that were essential for the methodology of teaching foreign languages, due to the goals of teaching: practical mastery of the language, communicative development of students, familiarization with cultural knowledge. So, we offer a refined typology of projects in foreign languages, taking into account the specifics of the formation of communicative competence.

\section{References}

1. Bakirova H.B. Teaching foreign language terminology at non-language universities. International journal of discourse on innovation. Integration and education. Volume: 01 Issue: 01.2020 http://summusjournals.uz/index.php/ijdiie

2. Bakirova H.B. Formation of terminological competence in ESP education. Novateur publications. Journal NX- A Multidisciplinary Peer Reviewed Journal, ISSN No: 2581 - 4230 VOLUME 6, ISSUE 11, India.-2020. P 63.

3. Zimnyaya I.A. Psychology of teaching foreign languages at school, 1991, p. 136. 